\title{
BMP9 (Bone Morphogenetic Protein 9) Induces NGF as an Autocrine/Paracrine Cholinergic Trophic Factor in Developing Basal Forebrain Neurons
}

\author{
Aletta C. Schnitzler, ${ }^{1}$ Tiffany J. Mellott, ${ }^{1}$ Ignacio Lopez-Coviella, ${ }^{1}$ Yvonne N. Tallini, ${ }^{2}$ Michael I. Kotlikoff, ${ }^{2}$ \\ Maximillian T. Follettie, ${ }^{3}$ and Jan Krzysztof Blusztajn ${ }^{1}$ \\ ${ }^{1}$ Department of Pathology and Laboratory Medicine, Boston University School of Medicine, Boston, Massachusetts 02118, ${ }^{2 B}$ Biomedical Science Department, \\ College of Veterinary Medicine, Cornell University, Ithaca, New York 14853, and ${ }^{3}$ Wyeth Research, Cambridge, Massachusetts 02140
}

Acetylcholine $(\mathrm{ACh})$ synthesis and release from basal forebrain cholinergic neurons (BFCN) innervating the cerebral cortex and hippocampus are essential processes for normal learning, memory and attention. Bone morphogenetic protein (BMP) 9 is a cholinergic differentiation factor in the developing septum that increases ACh synthesis and choline acetyltransferase (Chat) gene expression both in vivo and in vitro. We investigated the possible induction of cholinergic trophic factors by BMP9 in murine septal cells. Nerve growth factor (NGF) protein expression and secretion into the medium was increased in cultured embryonic septal cells treated with BMP9, and partially mediated BMP9-induced acetylcholine production and Chat gene expression. BMP9-induced Ngfgene expression was detected in postmitotic cells, required new protein synthesis and was blocked by BMP type I receptor inhibition. Cholinergic neurons were isolated by fluorescence-activated cell sorting based on either transgenic expression of green fluorescent protein driven by the Chat promoter or NGF receptor (p75) immunostaining. Although both noncholinergic and cholinergic neurons in untreated cultures expressed similar low levels of $\mathrm{Ngf}$, increased $\mathrm{Ng} f$ gene expression was restricted to Chat-positive neurons in BMP9-treated cultures. Likewise, similar levels of $N g f$ mRNA were detected in p75-negative and p75-postive septal cells, yet only p75-positive BFCN increased their $N g f$ gene expression when treated with BMP9, and only these cells expressed the Alk1 BMP receptor. The data suggest an autocrine/paracrine role for NGF in the development and/or maintenance of BFCN and imply that the stimulation of NGF production and release contributes to the cholinergic-supportive properties of BMP9.

\section{Introduction}

Basal forebrain cholinergic neurons (BFCN) project to the hippocampus and cerebral cortex where the release of their neurotransmitter, acetylcholine (ACh), is central for the processes of attention, learning and memory throughout life. During development, cholinergic innervation is necessary for the proper morphogenesis of target regions, and its early modulation has a lasting impact on adult behaviors (Leanza et al., 1996; Ricceri et al., 2002). Moreover, decline in BFCN function and cholinergic marker expression is apparent in Alzheimer's disease (AD) patients (Mufson et al., 2008), in aged animals and in genetic animal models of AD (Koh et al., 1989; Greferath et al., 2000; Cassel et al., 2008). Treatments for AD have focused on increasing cholinergic tone by inhibiting acetylcholinesterase. More recently, administration of trophic factors that support the function and survival cholinergic neurons has been explored (Tuszynski et al., 2005).

\footnotetext{
Received Nov. 12, 2009; revised April 16, 2010; accepted May 10, 2010.

This work was supported by National Institutes of Health Grants AG009525, AG032709, and DK065992. We thank Yanhui Deng and the Boston University Medical Center Flow Cytometry Core Facility for providing expertise in fluorescence-activated cell sorting.

Correspondence should be addressed to Jan Krzysztof Blusztajn at the above address. E-mail: jbluszta@bu.edu. D0I:10.1523/JNEUROSC1.5611-09.2010

Copyright $\odot 2010$ the authors $\quad 0270-6474 / 10 / 308221-08 \$ 15.00 / 0$
}

Neurotrophic factors are required for the development, maintenance and neuroprotection of BFCN. Nerve growth factor (NGF) in particular supports multiple aspects of cholinergic development and differentiation, including increasing the number and soma size of choline acetyltransferase (ChAT)-positive neurons and promoting neurite outgrowth and ChAT activity in neonatal septum, hippocampus and neocortex (Mobley et al., 1986; Hartikka and Hefti, 1988a; Sofroniew et al., 2001). Neonatal intraventricular administration of NGF increases the expression of Chat and Ntrk1, the gene that encodes the high-affinity NGF receptor TrkA, whereas administration of anti-NGF decreases the expression of both genes (Li et al., 1995). Though the primary source of NGF to BFCN is likely retrograde transport from target areas, predominantly the cortex and hippocampus (Sofroniew et al., 2001), NGF is also produced locally in the septum (Large et al., 1986; Saporito and Carswell, 1995). This source of NGF may be especially important during development of $\mathrm{BFCN}$ before they reach innervation targets.

Bone morphogenetic proteins (BMPs) play critical roles in CNS patterning, predominantly during early development (Liu and Niswander, 2005). BMPs bind to type I and type II TGF $\beta$ family receptors that primarily transduce signals via the Smad pathway (Liu and Niswander, 2005). BMP9 in particular is a cholinergic differentiation factor for BFCN. Application of BMP9 to both septal cell cultures and into the cerebral ventricles 
of developing mouse embryos significantly increases ACh production (López-Coviella et al., 2000). In various in vitro models BMP9 increases the expression of BFCN markers, in particular ChAT and, interestingly the low affinity NGF receptor (p75) (López-Coviella et al., 2000, 2005; Schnitzler et al., 2008a). Because prolonged exposure (days) to BMP9 is required to achieve its full effects on Chat expression and ACh production, we hypothesized that BMP9 may-at least in part-function by modulating the neurotrophic factor environment in favor of cholinergic development and maintenance. The data presented herein are consistent with this hypothesis.

\section{Materials and Methods}

Timed-pregnant CD-1 mice were obtained from Charles River Laboratories. Chat-eGFP mice, which express a bacterial artificial chromosome transgene containing eGFP at the Chat start site, were generated as previously described (Tallini et al., 2006). Recombinant human BMP9 was a gift from Wyeth Research. All reagents and chemicals were obtained from Sigma-Aldrich, unless otherwise noted.

Septal cell isolation and culture. Embryonic day 14 (E14) to E18 septa were dissected and dissociated as previously described (Schnitzler et al., $2008 \mathrm{a}, \mathrm{b})$. Cells were plated at a density of $1.25 \times 10^{5}$ cells per $\mathrm{cm}^{2}$ on poly-D-lysine/laminin-coated tissue culture-ware in 10\% FBS/DMEM supplemented $20 \mathrm{ng} / \mathrm{ml}$ bFGF (PeproTech), $50 \mathrm{U} / \mathrm{ml}$ penicillin and 50 $\mu \mathrm{g} / \mathrm{ml}$ streptomycin (pen/strep; Invitrogen), and cultured at $37^{\circ} \mathrm{C}$ in $5 \%$ $\mathrm{CO}_{2}$. Sixteen hours after plating, culture medium was changed to Neurobasal medium (NB, Invitrogen) containing 2\% B-27 (Invitrogen) supplement, $250 \mu \mathrm{M} \mathrm{L}$-glutamine, $250 \mu \mathrm{M}$ GlutaMax (Invitrogen), pen/strep, $20 \mathrm{ng} / \mathrm{ml}$ bFGF and $2 \mu \mathrm{M}$ cytosine arabinoside hydrochloride (AraC), unless otherwise noted. Cells were treated every $24 \mathrm{~h}$ or as indicated with BMP9, cycloheximide, Compound C, TrkA inhibitor (\#648450, Calbiochem), or anti-NGF antibody (Millipore, clone 27/21). Half the volume of media was exchanged every $48 \mathrm{~h}$. Cultured cells to be analyzed by fluorescence-activated cell sorting (FACS) were rinsed with PBS and trypsinized for $5 \mathrm{~min}$ at $37^{\circ} \mathrm{C}$. Cells were then briefly triturated through fire-polished, siliconized glass pipettes in 1:2:4 v/v 4\% BSA in PBS: $10 \%$ FBS in DMEM:Hibernate E medium containing $100 \mathrm{U} / \mathrm{ml}$ DNase. Finally, the cells were centrifuged through a $4 \%$ BSA/PBS cushion, and immunostained as described below.

FACS. E18 septal cells were sorted as previously described (Schnitzler et al., 2008b). Briefly, cells were stained at a concentration of $20 \times 10^{6}$ cells per $\mathrm{ml}$ in $0.2 \% \mathrm{BSA} /$ Hibernate $\mathrm{E}$ medium with $5 \mu \mathrm{g} / \mathrm{ml}$ anti-p75 affinity-purified antibody (Advanced Targeting Systems) for $35 \mathrm{~min}$ at $4^{\circ} \mathrm{C}$. Cells were washed with $0.2 \% \mathrm{BSA}$, and incubated with an Alexa 488-conjugated anti-rabbit-IgG secondary antibody (Invitrogen, 1:500) for $25 \mathrm{~min}$ at $4^{\circ} \mathrm{C}$. Cells were washed, and resuspended in $0.2 \% \mathrm{BSA}$ in Hibernate E medium before sorting on a MoFlo cell sorter (Dako Cytomation). Cells were collected into 20\% FBS/Hibernate E medium. Data were acquired and analyzed using Summit software (Dako Cytomation). All FACS dot plot $x$ - and $y$-axes indicate the fluorescence intensity.

Reverse transcriptase PCR. RNA for reverse transcriptase (RT)-PCR was isolated using an RNAqueous-micro kit according to the manufacturer's instructions (Ambion). RNA was quantified using the RiboGreen reagent (Invitrogen). RT-PCR was performed using the SuperScript One-Step with Platinum Taq kit (Invitrogen). Each reaction included 1.2-2.2 $\mathrm{mM} \mathrm{MgSO}_{4}$ and 10-50 ng of RNA. Reaction conditions were optimized for each primer set (see supplemental Figure S1, available at www.jneurosci.org as supplemental material, for primer sequences) such that product amplification fell within the linear range of both cycle number and RNA concentration. The RT-PCR products were electrophoresed through $1.8 \%$ agarose or $10 \%$ acrylamide gels at $100 \mathrm{~V}$, visualized with ethidium bromide on an ImageStation 440CF (Kodak) and analyzed with Kodak 1D Image Analysis software.

Immunoblotting. Cells were lysed in buffer containing $50 \mathrm{~mm}$ Tris $\mathrm{pH}$ $7.5,150 \mathrm{~mm} \mathrm{NaCl}, 1 \% \mathrm{NP}-40,0.2 \%$ SDS, 0.5\% deoxycholic acid, $1 \mathrm{~mm}$ $\mathrm{Na}_{3} \mathrm{VO}_{4}, 25 \mathrm{~mm} \mathrm{NaF}$ and $1 \%$ protease inhibitor cocktail (\#P8340, Sigma). Equal amounts $(4-10 \mu \mathrm{g})$ of each sample was electrophoresed through $10 \%$ Bis-Tris precast gels (Invitrogen) and transferred to blot- ting membrane using the iBlot system (Invitrogen). Membranes were blocked with $4 \%$ milk in PBS/0.1\% Tween (PBS-T), washed with PBS-T and probed with anti-phospho-SMAD1/5/8 (1:1000, Santa Cruz Biotechnology) or anti- $\beta$-actin (1:2000) followed by species-specific antiIgG-HRP (1:5000, Bio-Rad). Reactive bands were detected with SuperSignal West Femto chemiluminescent substrate (Pierce), captured with an ImageStation 440CF and their intensities quantified with Kodak 1D Image Analysis software.

ELISA. Whole-cell extracts were prepared in lysis buffer containing $137 \mathrm{~mm} \mathrm{NaCl}, 20$ mм Tris $\mathrm{pH}$ 8.0, 1\% NP-40, 10\% glycerol, $1 \%$ protease inhibitor cocktail and $1 \mathrm{~mm}$ phenylmethylsulfonyl fluoride. Samples were acidified to $\mathrm{pH} 2.6$ for $15 \mathrm{~min}$ at room temperature, then neutralized to $\mathrm{pH}$ 7.6. The medium from each culture dish was concentrated tenfold before ELISA using Amicon Ultra centrifugal filter devices (5000 MWCO, Millipore). IGF-1 was assayed using the Quantikine sandwich ELISA kit (R\&D Systems), and NGF and NT-3 were assayed using the Emax immunoassay system (Promega), according to manufacturer's instructions. As the immunogen for the anti-NGF detection antibody is the $2.5 \mathrm{~S}$ mNGF, this ELISA may also detect proNGF. The trophic factor levels in the media are expressed as the original concentrations in culture.

Acetylcholine assay. Cellular acetylcholine levels were determined by HPLC as previously detailed (López-Coviella et al., 2000). Briefly, cells were incubated in physiological salt solution containing $15 \mu \mathrm{M}$ choline and $15 \mu \mathrm{M}$ neostigmine for $1 \mathrm{~h}$ at $37^{\circ} \mathrm{C}$. Cells were washed and collected into $100 \% \mathrm{MeOH}$. Precipitated proteins were removed by centrifugation and the supernatant was chloroform extracted. The aqueous layer was lyophilized, then resuspended in $\mathrm{diH}_{2} \mathrm{O}$ and subject to analysis by HPLC.

Statistics. The statistical significance of changes in protein levels, mRNA expression and ACh content was determined by one-way or two-way ANOVA, as appropriate. All post hoc analysis were done using Fisher's least-significant-difference test, with $p \leq 0.05$ deemed as significant. Specific $\mathrm{p}$ values are noted in the figure legends. All error bars indicate the SEM.

\section{Results \\ BMP9 modulates the trophic factor profile of basal forebrain cultures}

Trophic factors known to play various roles in the development and support of BFCN were examined in murine septal cell cultures in response to BMP9. Cultures were established from cells isolated at E14 (when Chat expression is very low in vivo), E16 and E18 (after many cholinergic neurons have developed in the septum). After $4 \mathrm{~d}$ in vitro, cell lysates and culture media were examined by ELISA for levels of NGF, NT-3 and IGF-1 protein. The addition of BMP9 to the culture media significantly increased the amount of NGF protein both within cells and released into the culture medium at all developmental stages examined (Fig. $1 A, B$ ). Intracellular NT-3 levels were significantly decreased by BMP9 treatment at later embryonic stages, while IGF-1 was unaffected. The ELISA results were in agreement with the modulation of $\mathrm{Ngf}$ and $\mathrm{Ntf3}$ (encoding NT-3) gene expression by BMP9 (Fig. 1C). As mRNA and protein levels were examined at the same time point, the modest increase in Igfl gene expression may not have been translated into detectable increases in protein.

To ensure that the expression of $\mathrm{Ngf}$ in septal cells shown here is not a culture-specific phenomenon its expression was also evaluated in uncultured septal tissue over a range of developmental stages, and was found to peak at or $\sim$ P8 (supplemental Fig. S2 A, available at www.jneurosci.org as supplemental material). Various early postnatal brain regions were also examined. Though $N g f$ expression was markedly lower in the septum than in the hippocampus, it was comparable to that measured in the frontal cortex and cerebellum (supplemental Fig. S2 B, available at www. jneurosci.org as supplemental material). 

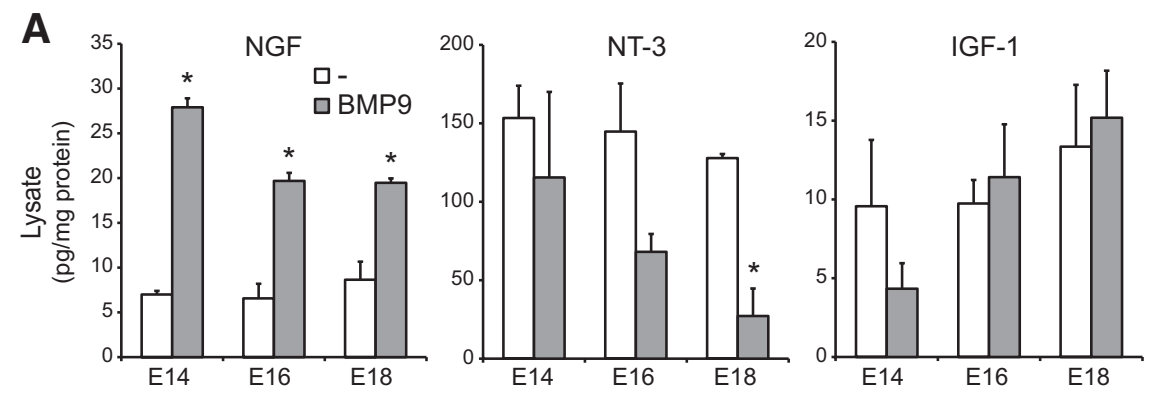

B

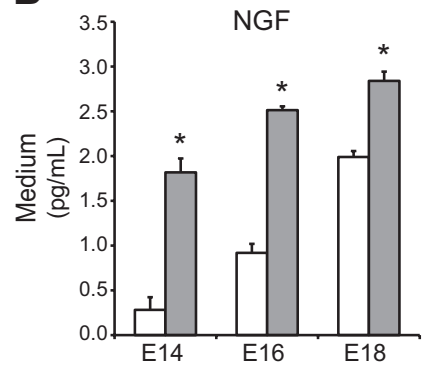

C
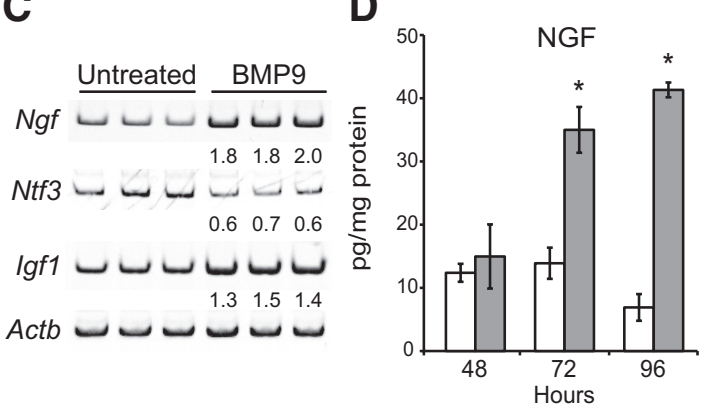

Figure 1. BMP9 stimulates NGF production by embryonic septal cells. Septal cells from E14, E16, or E18 embryos were cultured for $4 \mathrm{~d}$ in the presence or absence of BMP9 $(100 \mathrm{ng} / \mathrm{ml})$. $\boldsymbol{A}$, Cell lysates were analyzed by ELISA for protein levels of NGF, NT-3 and IGF-1. ${ }^{*} p<0.05$ compared with untreated samples, $n=3$. $\boldsymbol{B}$, Culture medium was analyzed by ELISA for secreted NGF. ${ }^{*} p<0.01$ compared with untreated samples, $n=3$. C, Corresponding changes in Ngf, Ntf3 (NT-3-encoding gene) and Igf1 mRNA expression were confirmed by RT-PCR in E14 samples. Fold change from the average value of untreated controls normalized to $A c t b$ ( $\beta$-actin) are indicated below each BMP9-treated sample. D, E14 septal cells were cultured with or without BMP9 $(100 \mathrm{ng} / \mathrm{ml})$ in the absence of cytosine arabinoside for the indicated times followed by ELISA analysis for NGF protein levels in cell lysates. * $p<0.01$ compared with untreated samples, $n=3$.

\section{BMP9-induced $N g f$ expression in postmitotic cells, requires new protein synthesis and is mediated by the canonical BMP signaling pathway}

A delay in the increased production of NGF protein following BMP9 treatment was observed when shorter duration cultures were examined (Fig. 1D), which correlated with a delay in increased $N g f$ mRNA levels (Fig. $2 \mathrm{~A}$, control). We hypothesized that this delay was due to either the production of BMP9-induced NGF by dividing cells that can accumulate in septal cultures over time, or an intermediate factor that must accumulate to mediate the effects of BMP9. Blocking the expansion of dividing cells with the cytostatic agent AraC neither prevented the delay in BMP9induced $N g f$ expression nor affected the degree of its induction ultimately achieved (Fig. 2A, 2.2-fold at $96 \mathrm{~h}$ ). As expected, the inclusion of cytosine arabinoside (AraC) in the culture medium yielded a more neuronal cell population as indicated by an $\sim 2.5$ fold higher Tubb3 ( $\beta$-3-tubulin) expression compared with control cultures (Fig. $2 B$ ). Likewise, the relative levels of $N g f$ were $\sim 2.5$-fold higher in the presence of AraC compared with the control cultures, independent of BMP9 treatment (Fig. 2 B). This suggests that postmitotic cells are primarily responsible for the production of NGF in septal cultures. Moreover, the expression of a glial cell marker, glial fibrillary acidic protein ( $G f a p$ ) was abolished by the addition of AraC (supplemental Fig. S3, available at www.jneurosci.org as supplemental material), indicating that glial cells are not responsible for the expression of $\mathrm{Ng}$ in the cultures. Conversely, the addition of the protein synthesis inhibitor cycloheximide (CHX) completely abolished the effect of BMP9 on the expression of $N g f$ mRNA (Fig. $2 A, B$ ), demonstrating that the synthesis of an intermediate factor is necessary for BMP9-induced Ngf gene expression. Although basal expression of
Id3 - an immediate downstream target of the Smad signaling pathway activated by BMP9 - was reduced in cultures containing AraC and CHX, it was still greatly increased by BMP9 (Fig. 2B), indicating that BMP signaling remains intact under both conditions.

The expression of $I d$ genes is robustly induced by BMPs via Smad1/5/8 phosphorylation (Hollnagel et al., 1999; Yu et al., 2008). To assess whether BMP9 is using this canonical pathway of BMP signaling to increase $N g f$ gene expression, the BMP type I receptor inhibitor, compound $\mathrm{C}$ [also known as dorsomorphin (Yu et al., 2008)] was used. Pretreatment of septal cultures with $10 \mu \mathrm{M}$ compound C blocked Smad1/5/8 phosphorylation in shortterm septal cultures treated with BMP9 (Fig. 3A). Because this concentration of compound $\mathrm{C}$ was toxic in long-term cultures, lower concentrations were used to assess its effect on BMP9-induced $\mathrm{Ng}$ mRNA levels. BMP9-induced expression of both $I d 3$ and $N g f$ genes was inhibited in a concentration-dependent manner. BMP9induced $N g f$ expression was significantly less in samples containing 1.0 and $2.5 \mu \mathrm{M}$ compound $\mathrm{C}$ than in samples containing no inhibitor. In addition, compound $\mathrm{C}$ at $0.1,1.0$ and $2.5 \mu \mathrm{M}$ significantly inhibited BMP9-induced Id3 expression (Fig. 3B). These data indicate that BMP9 signaling through the BMP type I receptor pathway is required for the induction of $\mathrm{Ngf}$ expression.

\section{NGF contributes to BMP9-stimulated ACh production}

The modulation of cholinergic properties of septal neurons by BMP9 bears similarity to the actions of NGF in a variety of ways including increased ACh production and Chat expression. We therefore evaluated whether BMP9-induced NGF contributes to the phenotypic effects of BMP9 by blocking NGF function in BMP9-treated cultures. BMP9-induced ACh production was reduced by a TrkA kinase inhibitor (Calbiochem \#648450) in a concentration-dependent fashion by as much as $46 \%$ (Fig. $4 \mathrm{~A}$, $\left.{ }^{*} p=0.0001\right)$. The TrkA inhibitor also slightly decreased basal levels of ACh in the absence of BMP9, though this reduction did not achieve significance $(\dagger p=0.15)$. To determine whether NGF also contributes to BMP9-modulated gene expression, a highly specific NGF neutralizing antibody (anti-NGF) was added to septal cultures before and during BMP9 treatment. This antibody completely blocks NGF-induced TrkA phosphorylation in septal cultures (data not shown). In the presence of anti-NGF the BMP9-induced Chat expression was reduced by $45 \%$ (Fig. $4 B$, $\left.{ }^{*} p=0.006\right)$, similar to the magnitude of the decrease in ACh content observed with the TrkA inhibitor. In contrast, anti-NGF did not alter BMP9-induced changes in $\mathrm{Ngfr}$ (the gene encoding p75), Id3 or Ntrk1 mRNA expression.

\section{BMP9-induced Ngf is restricted to cholinergic neurons}

Studies performed in adult rats show that $N g f$ mRNA is expressed at low levels in the basal forebrain (Large et al., 1986; Shelton and Reichardt, 1986; Lauterborn et al., 1991; Saporito et al., 1994; Saporito and Carswell, 1995), and detected primarily in GABAergic 
A

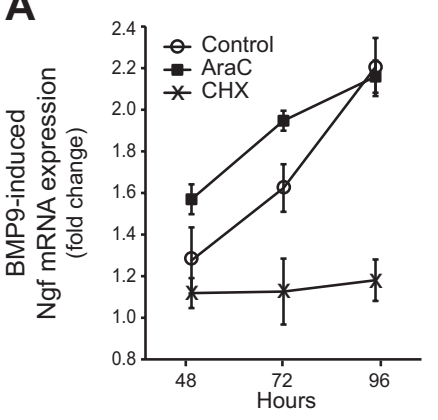

B

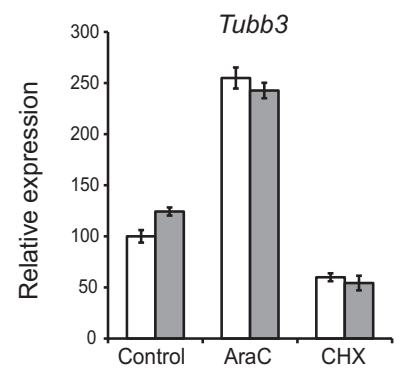

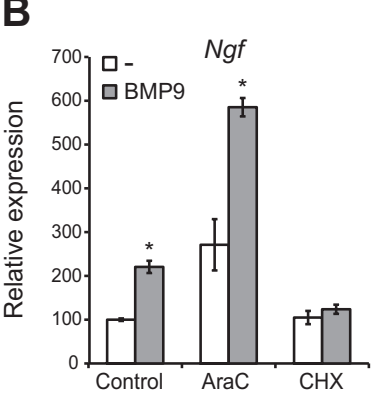

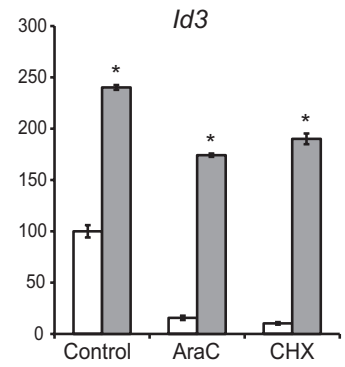

Figure 2. BMP9-induced Ngfis detected in postmitotic cells and is dependent on new protein synthesis. Septal cells from E14 embryos were cultured in control medium or medium containing AraC $(2 \mu \mathrm{m})$ or CHX (1 $\mu \mathrm{g} / \mathrm{ml})$. A, BMP9-induced Ngf mRNA expression was evaluated by RT-PCR at the indicated times. $\boldsymbol{B}, \mathrm{Ngf}, \mathrm{Id} 3$ and $T u b b 3 \mathrm{mRNA}$ expression in untreated and BMP9-treated cultures was evaluated after $4 \mathrm{~d}$ in vitro. ${ }^{*} p<0.01$ compared with untreated samples, $n=3$.

A

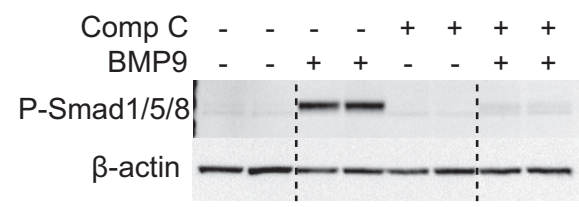

B
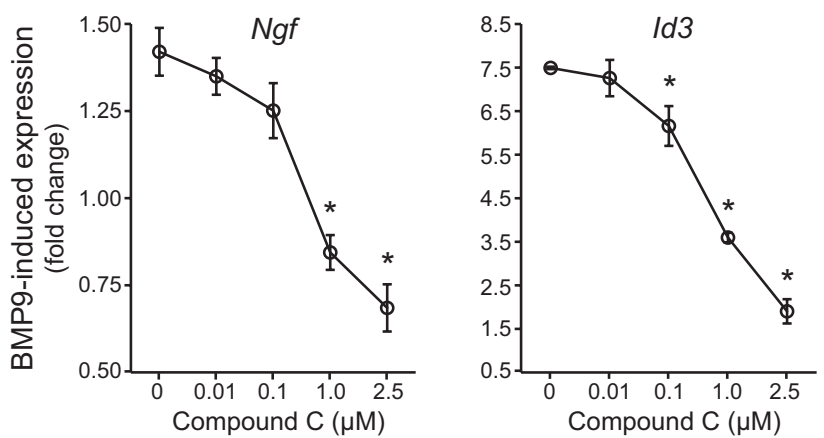

Figure 3. BMP type 1 receptor signaling is required for BMP9-induced Ngf expression. $A$, E14 septal cells were cultured for $2 \mathrm{~d}$, then pretreated with Compound C (Comp C, $10 \mu \mathrm{m})$ for $30 \mathrm{~min}$, at which time BMP9 $(20 \mathrm{ng} / \mathrm{ml})$ was added to the cultures for an additional $30 \mathrm{~min}$. PhosphoSmad1/5/8 levels were evaluated by immunoblot in whole-cell lysates of duplicate samples. The blot was also probed for $\beta$-actin to confirm equal loading. Dashed lines indicate the removal of unrelated sample lanes from the gel images. $\boldsymbol{B}$, E14 septal cultures were treated for 30 min with Compound C as indicated before the addition of BMP9 $(10 \mathrm{ng} / \mathrm{ml})$. Cultures were re-treated every $24 \mathrm{~h}$ and harvested after $4 \mathrm{~d}$ in vitro. $\mathrm{Ngf}$ and $/ \mathrm{d} 3 \mathrm{mRNA}$ levels were evaluated by RT-PCR and expressed as fold change. ${ }^{*} p<0.02$ compared with fold increase in samples with no inhibitor, $n=3$.

neurons (Lauterborn et al., 1995). The expression of $\mathrm{Ng}$ is not well characterized during development, but it has been detected in the basal forebrain during both embryonic and postnatal periods (Large et al., 1986; Lüesse et al., 1998; Formaggio et al., 2010).
A
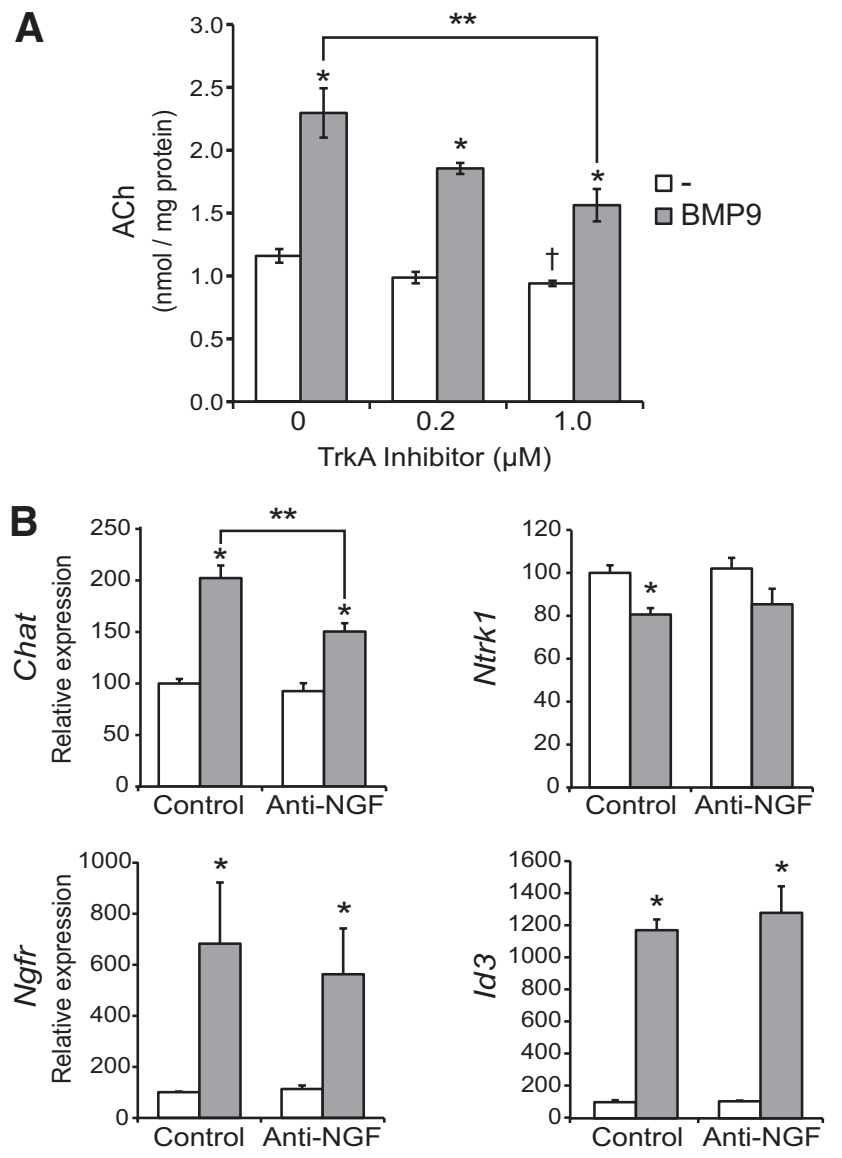

Figure 4. BMP9-induced NGF is an autocrine/paracrine factor that stimulates ACh production and Chat expression. $\boldsymbol{A}, \mathrm{E} 14$ septal cells were pretreated with a TrkA kinase inhibitor at the indicated concentrations and cultured in the absence or presence of BMP9 $(100 \mathrm{ng} / \mathrm{ml})$ for $4 \mathrm{~d}$, followed by HPLC analysis of cellular ACh. ${ }^{*} p \leq 0.01$ compared with BMP9-untreated samples, $n=4 .{ }^{* *} p=0.0001$. $B$, E14 septal cell cultures were pretreated with a NGF neutralizing antibody (Anti-NGF, $1 \mu \mathrm{g} / \mathrm{ml}$ ) then treated with or without BMP9 $(100 \mathrm{ng} / \mathrm{ml})$ for $4 \mathrm{~d}$. Samples were analyzed by RT-PCR for expression of the indicated genes. ${ }^{*} p<0.05$ compared with BMP9-untreated samples, $n \geq 3$. ${ }^{* *} p=0.006$.

We hypothesized that embryonic septal cells induced to express Ngf by BMP9 in vitro would be restricted to either a cholinergic or noncholinergic phenotype. To test this, E14 septal cells from transgenic mice that express enhanced green fluorescent protein (eGFP) under the control of the Chat promoter (ChateGFP) (Tallini et al., 2006) were cultured with or without BMP9 in the presence of AraC for $4 \mathrm{~d}$. Fluorescent and phase contrast photomicrographs of the BMP9-treated culture revealed a highly neuronal population of both cholinergic and noncholinergic neurons that have elongated processes (Fig. 5A). Cultures were further analyzed by flow cytometry. Although Chat expression is minimal in septal neurons at E14, after $4 \mathrm{~d}$ in vitro we detected fluorescence in $5.7 \%$ of the cultured cells (Fig. $5 B$, top). This likely represents cells already set on a cholinergic differentiation pathway at the time of isolation, or the differentiating influence of endogenous factors or factors present in the basal culture medium. Septal cells treated with BMP9 had almost twice as many $\mathrm{eGFP}^{+}$cholinergic neurons (9.2\%; Fig. 5B, bottom). Interestingly, the mean fluorescent intensity (MFI) of the cholinergic neurons was similar in both samples (untreated: 143, BMP9: 156) indicating that BMP9 is primarily inducing new cells to express Chat rather than increasing its level of expression in already cholinergic neurons. These $\mathrm{eGFP}^{-}$and $\mathrm{eGFP}^{+}$cell populations ob- 
A

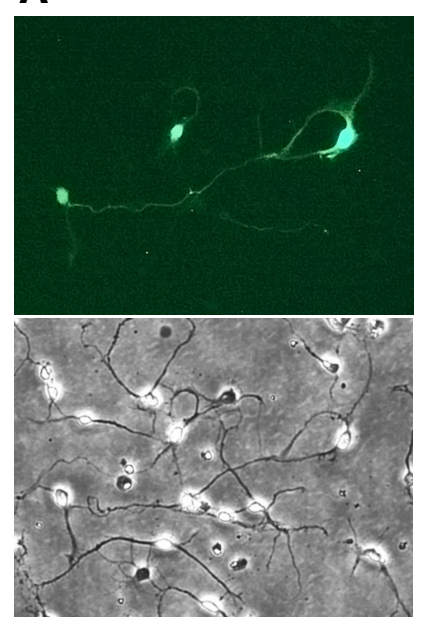

B

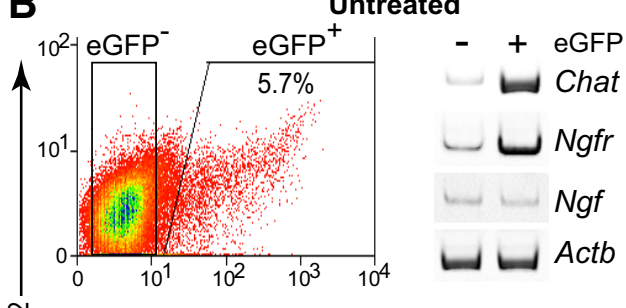

บิ

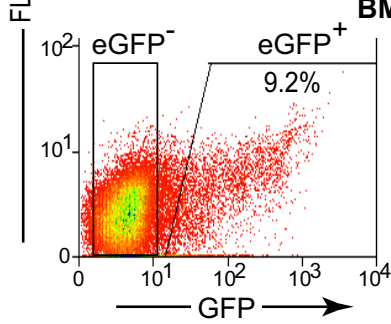

BMP9
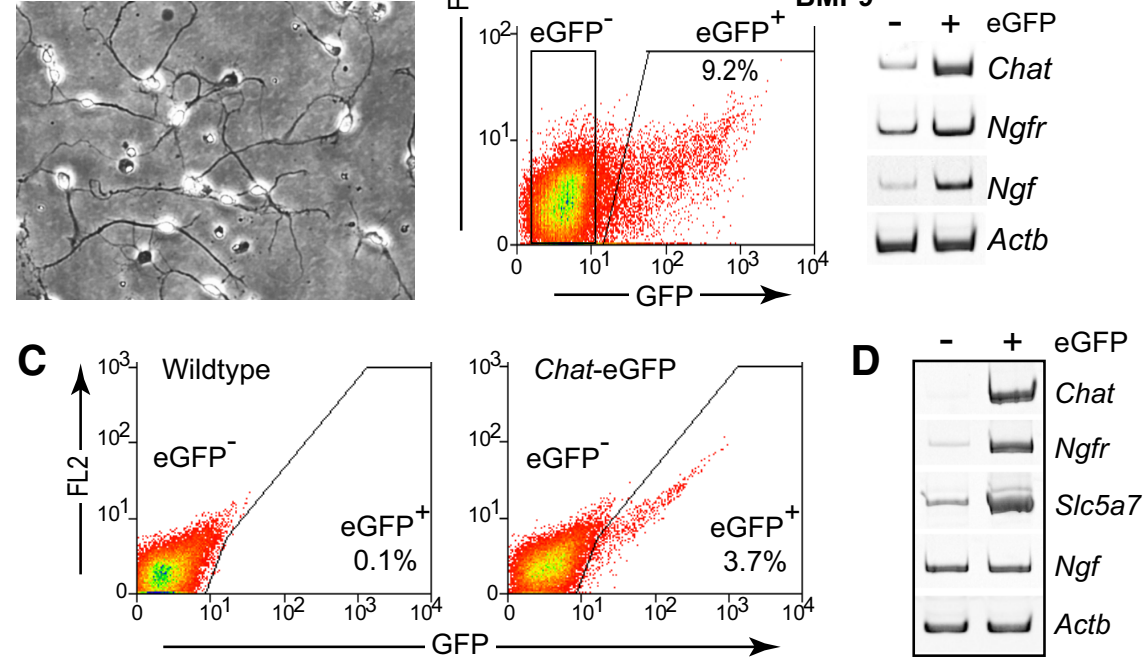

Figure 5. BMP9-induced Ngf is expressed in cholinergic neurons. E14 septal cells from Chat-eGFP mice were cultured for $4 \mathrm{~d}$ in the absence or presence of BMP9 $(100 \mathrm{ng} / \mathrm{ml})$, then examined by microscopy, FACS, and RT-PCR. $A$, Fluorescence (top) and phase contrast (bottom) microscopy images of the live BMP9-treated culture. B, Both the untreated and BMP9-treated cultures were FACS-sorted into eGFP ${ }^{-}$and eGFP ${ }^{+}$populations that were then examined for gene expression by RT-PCR. The FACS dot plots indicate the percentage of cholinergic neurons in each culture. C, Septal cells from P0 wild-type or Chat-eGFP mice were analyzed by flow cytometry. The percentage of cells within the eGFP ${ }^{+}$region is indicated on each dot plot. D, eGFP ${ }^{-}$and eGFP ${ }^{+}$cells from E18 septa were purified by FACS; their RNA was immediately extracted and then analyzed by RT-PCR for expression of the indicated genes.

tained by FACS following a $4 \mathrm{~d}$ culture period in the presence and absence of BMP9 were then examined by RT-PCR to measure gene expression levels. As expected, the cholinergic neurons were greatly enriched in Chat and $N g f r$ mRNA expression compared with noncholinergic cells (Fig. 5B). $N g f$ expression was detected at low levels in both the cholinergic and noncholinergic populations collected from the untreated culture. Surprisingly, increased $N g f$ expression in the BMP9-treated culture was restricted to cholinergic neurons (fold changes in duplicate experiments: $\left.\mathrm{eGFP}^{-}=1.0 \pm 0.1, \mathrm{eGFP}^{+}=9.5 \pm 1.2\right)$, suggesting that these cells are the source of the functional NGF measured above. Consistent with the similar MFIs of cholinergic neurons isolated from untreated and BMP9-treated cultures, these two populations of cholinergic neurons expressed similar levels of Chat mRNA (Fig. 5B). Gfap expression was not detectable in any sample (data not shown).

The expression of $N g f$ mRNA in cholinergic neurons from the developing forebrain was confirmed in freshly isolated cells from Chat-eGFP mice. A distinct set of $\mathrm{eGFP}^{+}$cells is present in the septal cell population of Chat-eGFP mice (Fig. 5C), whereas fluorescence is not detectable in cells from this region of wild-type mice. As expected, freshly isolated FACS-sorted eGFP ${ }^{+}$cells from E18 Chat-eGFP mice are highly enriched in expression of the cholinergic markers Chat, $\mathrm{Ngfr}$ and Slc5a7 (the high-affinity choline transporter, Fig. 5D). Ngf was equally expressed in the cholinergic and noncholinergic populations.
BMP9-induced $\mathrm{Ng} f$ expression becomes restricted to late embryonic $\mathrm{p} 75^{+}$basal forebrain neurons in correlation with their expression of $A l k 1$

Maturing BFCN were purified at E18 using FACS based on cell surface levels of p75, a well established marker for BFCN in the septum (Dawbarn et al., 1988; Hartikka and Hefti, 1988b; Heckers et al., 1994; Lin et al., 2007). Approximately $7.5 \%$ of the E18 septal cell population had detectable p75 protein labeling (Fig. 6A). The $\mathrm{p} 75^{-}$and $\mathrm{p} 75^{+}$populations were collected and cultured under conditions previously shown to maintain a highly neuronal cell population (Schnitzler et al., 2008a,b). The cultured $\mathrm{p} 75^{+}$and $\mathrm{p} 75^{-}$ neurons maintained similar levels of $\mathrm{Ngf}$ mRNA (Fig. 6B), yet BMP9 treatment only increased $\mathrm{Ngf}$ levels in $\mathrm{p} 75^{+}$cells. This result suggests that even though $\mathrm{Ngf}$ is expressed in, at least some, cholinergic and noncholinergic septal cells, the further augmentation of $N g f$ expression by BMP9 is also restricted to BFCN during late embryogenesis. Importantly, the highly enriched expression of Ntrk1 in $\mathrm{p} 75^{+}$septal neurons was maintained with BMP9 treatment (Fig. 6C).

Because the pattern of TGF $\beta$ receptor expression fine-tunes responses to BMPs, we compared the levels of select receptors in $75^{-}$and p $75^{+}$septal cells (Fig. 6D). Interestingly only $\mathrm{p}^{+}$cells expressed the mRNA for the type I BMP9 receptor, Alk1/Acvrl1 (Brown et al., 2005), while p75 ${ }^{-}$cell were devoid of this message. The expression of the other type I BMP receptors (Alk2/Acvr1, Alk3/Bmpr1a, Alk4/Acvr1b and Alk6/Bmprlb) and of the type II receptors (Bmpr2, Acvr2a/ActrII and Acvr2b/ActrIIb) was similar in $\mathrm{p} 5^{+}$and $\mathrm{p} 75^{-}$cells. These data point to ALK1 as a novel marker for BFCN and suggest that ALK1 might mediate the upregulation of NGF production in response to BMP9 specifically in the $\mathrm{p} 75^{+}$neurons.

\section{Discussion}

The central findings of this study are that $N g f$ mRNA is expressed in cholinergic (Chat- or p75-expressing) and noncholinergic cells of the developing basal forebrain, and that in vitro BMP9 stimulates the expression and release of NGF that contributes to the BMP9-induced upregulation of the cholinergic phenotype of BFCN. The restriction of BMP9-induced Ngf expression to cholinergic neurons suggests and autocrine/paracrine function of NGF in this system. In addition, these data together with our observation that BMP9 dramatically reduces the production of NT3 and increases Igf1 mRNA levels in septal cultures point to a novel mode of BMP9 action, i.e., modulation of the trophic environment of developing basal forebrain neurons. Consistent with previous results (López-Coviella et al., 2005; Schnitzler et al., 2008a), the Ngfr mRNA and cell surface protein levels rose severalfold in cells treated with BMP9. The increased expression of $N g f r$ would be expected to potentiate NGF signaling via TrkA (Canossa et al., 1996). Conversely, p75 can act as mediator of 
A
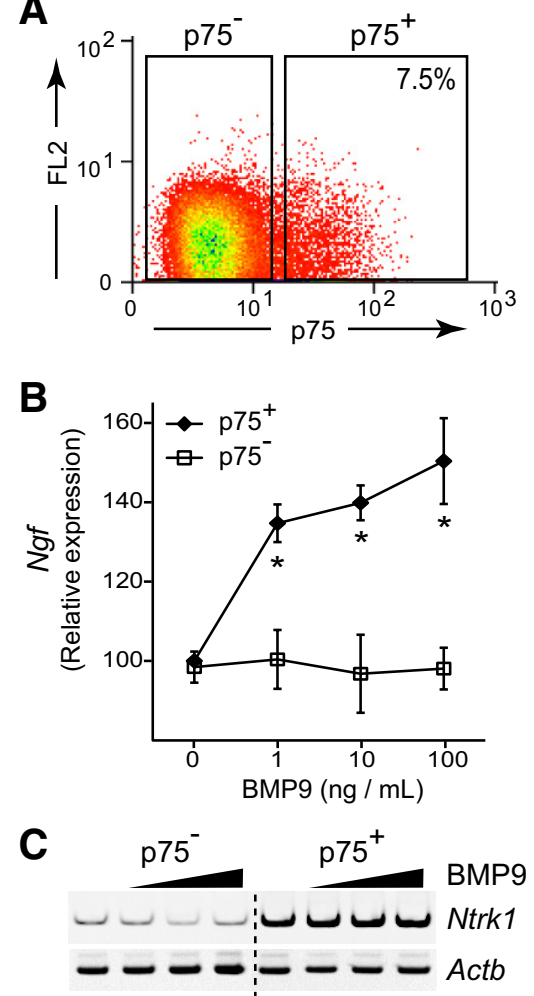

D

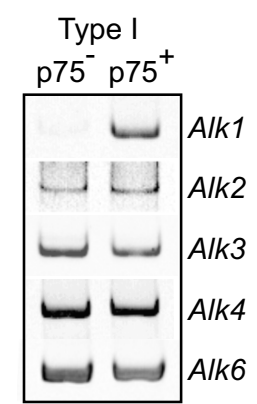

Type II

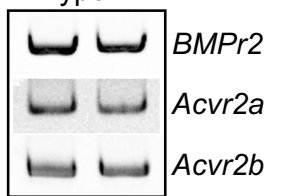

Controls

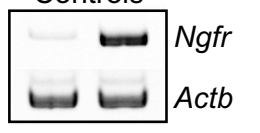

Figure 6. Augmentation of $\mathrm{Ng}$ fexpression by BMP9 in mature, p75-expressing BFCN. A, Freshly isolated E18 septal cells were immunostained and FACS sorted based on levels of surface p75 protein. The percentage of cells within the $75^{+}$region is indicated on the dot plot. $\boldsymbol{B}, \boldsymbol{C}$, The $\mathrm{p} 75^{-}$and $\mathrm{p} 75^{+}$cells were cultured for $4 \mathrm{~d}$ in the absence or presence of BMP9 at the indicated concentrations, then analyzed by RT-PCR for Ngf gene expression $\left({ }^{*} p<0.01\right.$ compared with untreated samples, $n=3)(\boldsymbol{B})$ or Ntrk1 expression $(\boldsymbol{C})$ (dashed line indicates a discontinuous point in the gel images). D, Freshly isolated E18 $\mathrm{p} 75^{-}$and $\mathrm{p} 75^{+}$cells were examined by RT-PCR for expression of type I and type II BMP receptor genes.

apoptosis (Dechant and Barde, 2002; Chao, 2003) and, when secreted by cells, as a possible soluble inhibitor of NGF (Weskamp et al., 2004). BMP9 also induces the expression of noggin (López-Coviella et al., 2005), a soluble antagonist of BMP action. These observations demonstrate that BMP9 also regulates the expression of molecules that govern BFCN responses to NGF and BMPs.

NGF-evoked induction of Chat and upregulation of ACh production requires Ntrk1 expression and activity (Berse et al., 1999), and indeed the increase of cellular ACh levels evoked by the BMP9-induced NGF synthesis was sensitive to TrkA inhibition. TrkA is a marker of the cholinergic cell bodies in the septum and NGF infusion in vivo elicits TrkA phosphorylation, increases the size of cholinergic neurons and stimulates Chat expression ( $\mathrm{Li}$ et al., 1995). BMP9 appears to target the already differentiated cholinergic neurons at later embryonic stages to increase NGF expression. As these neurons are highly enriched in Ntrk 1 expression, an autocrine system that can be modulated by BMPs is implicated. Moreover, BMP9 increases Chat mRNA expression in SN56T17 cells (López-Coviella et al., 2000) and in purified p75-expressing BFCN (Schnitzler et al., 2008a), suggesting that its action does not require the presence of auxiliary cells.

The possibility of a NGF/TrkA-mediated autocrine system was previously suggested by studies on the cell bodies of layer $\mathrm{V}$ pyramidal neurons of the adult rat cortex where dual fluorescent in situ hybridization and immunolabeling of histological sections revealed coexpression of $N g f$ mRNA and phospho-TrkA protein
(Bruns and Miller, 2007). During adulthood, NGF supplied to the basal forebrain via retrograde transport from the target regions is a major source of the growth factor (Sofroniew et al., 2001). However, during development efferents from the septum to the hippocampus are first detected in late embryonic stages, and the adult pattern of innervation is not established until after P10 (Linke and Frotscher, 1993). Though the administration of exogenous NGF to adult mice with a single disrupted $\mathrm{Ng} f$ allele can ameliorate select behavioral and morphological deficits associated with NGF haploinsufficiency, it does not rescue the reduced cholinergic cell number in the septum (Chen et al., 1997). Together, these data suggest that NGF deficiency during development can permanently alter neural architecture in the mature animal, and that the locally derived NGF reported here may be particularly important during developmental stages before complete target innervation.

At least one cell type that produces neurotrophins in the developing forebrain has been identified. Astrocytes isolated from the $\mathrm{P} 1$ rodent forebrain express NGF, BDNF and NT-3, and can modulate their expression in response to a variety of neuronal signals (Wu et al., 2004). Astrocytes in other brain regions have been shown to express p75, raising the questions whether the increased NGF expression that we detect in $\mathrm{p} 75^{+}$cells from the septum is due to an early astrocytic cell population. Even though there is no published evidence that embryonic astrocytes in the septum express p75, our data do not eliminate this possibility. However, the continued strong expression of Ntrk1 in the purified $\mathrm{p}^{+} 5^{+}$cells in culture, the expression of $\mathrm{Ng}$ in freshly purified Chat-eGFP ${ }^{+}$BFCN, its induction by BMP9 in Chat-eGFP ${ }^{+}$ BFCN isolated from E14 cultures, concomitant with the apparent absence of glial cells in the cultures (as determined by undetectable levels of Gfap mRNA) support an autocrine paradigm.

We found several type I and type II BMP receptors expressed in both $\mathrm{p} 75^{-}$and $\mathrm{p} 75^{+}$cells from the prenatal mouse septum, some of which are reportedly responsive to BMP9 (Massagué, 2008). These receptors are likely responsible for the robust induction of cholinergic genes in p $75^{-}$septal cells by BMP9 (Schnitzler et al., 2008a). The current results also show that $\mathrm{p} 75^{+}$cells express Alk 1 while $\mathrm{p}^{-} 5^{-}$do not and thus point to the possibility that ALK1 is responsible for the specific induction of NGF by BMP9 in maturing BFCN ( $\mathrm{p} 75^{+}$cells). The restricted expression of $A l k 1$ to $\mathrm{p} 75^{+}$cells may also make it a useful marker for at least a subset, if not all, cholinergic neurons in the developing septum. Importantly, ALK1 has been shown to interact directly with BMP9 (Brown et al., 2005), and is sensitive to compound C (Upton et al., 2009) - a type I receptor inhibitor that abolished BMP9activated SMAD1/5/8 phosphorylation as well as $I d 3$ and $N g f$ induction. Moreover, our previous studies showed that SMAD1 and SMAD5 are robustly expressed in the fetal septum, and both become highly phosphorylated, form a complex with SMAD4 and translocate to the nucleus in E14 septal cells treated with BMP9 (López-Coviella et al., 2006). Thus, the broadly defined canonical BMP signaling pathway is activated by BMP9 in septal cells and is likely required for BMP9-induced Ngf expression.

The induction of $N g f$ mRNA in septal cultures by BMP9 was abolished by treatment with $\mathrm{CHX}$, indicating that it required the synthesis of a protein mediator-possibly a transcription factor. BMP9 rapidly stimulates the expression of multiple transcriptional regulators and several of these molecules are critical for normal neuronal development, including Gata2, Msx1, Msx2, Zfp423 (Roaz), Id1 and Id3 (López-Coviella et al., 2005). In the current study we used the expression of the latter as an example of a direct target gene (i.e., insensitive to $\mathrm{CHX}$ ) of BMP action. 
There are no data on the regulation of $N g f$ expression by these proteins, however they constitute a set of targets for further studies. Another potential candidate may be $\mathrm{p} 75$ which is upregulated by BMP9, and has been shown to affect transcriptional signaling pathways after proteolytic release of its intracellular domain (Kanning et al., 2003), though there is currently no evidence that this mechanism regulates $N g f$ expression. In addition to transcription factors, BMP9 may modulate the expression of diffusible molecules that affect NGF production. For example, we reported that BMP9 upregulates the expression of ciliary neurotrophic factor ( $\mathrm{Cntf}$ ) in septal cultures (López-Coviella et al., 2005), a protein that increases $N g f$ expression in astrocytes (Semkova and Krieglstein, 1999), Ngfr expression in septal cultures (Magal et al., 1991) and Chat expression in sympathetic neurons (Saadat et al., 1989). Moreover, BMPs have been shown in a number of nervous system regions and experimental models to interact functionally with neurotrophins to promote neuronal survival and function. For example, BMPs synergize with neurotrophins to preserve ChAT activity in cultured embryonic septal neurons under hypoglycemic stress (Nonner et al., 2001). It is possible that BMP9 not only increases the production of NGF, but also enhances its efficacy. The current results that BMP9 specifically targets BFCN to express Ngf together with data showing BMP9 can increase ChAT activity, ACh production and $\mathrm{Ng} r$ expression suggest a multifactorial role for BMP9 in supporting the cholinergic phenotype.

\section{References}

Berse B, Lopez-Coviella I, Blusztajn JK (1999) Activation of TrkA by nerve growth factor upregulates expression of the cholinergic gene locus but attenuates the response to ciliary neurotrophic growth factor. Biochem J 342:301-308.

Brown MA, Zhao Q, Baker KA, Naik C, Chen C, Pukac L, Singh M, Tsareva T, Parice Y, Mahoney A, Roschke V, Sanyal I, Choe S (2005) Crystal structure of BMP-9 and functional interactions with pro-region and receptors. J Biol Chem 280:25111-25118.

Bruns MB, Miller MW (2007) Functional nerve growth factor and trkA autocrine/paracrine circuits in adult rat cortex are revealed by episodic ethanol exposure and withdrawal. J Neurochem 100:1155-1168.

Canossa M, Twiss JL, Verity AN, Shooter EM (1996) p75(NGFR) and TrkA receptors collaborate to rapidly activate a p75(NGFR)-associated protein kinase. ЕMBO J 15:3369-3376.

Cassel JC, Mathis C, Majchrzak M, Moreau PH, Dalrymple-Alford JC (2008) Coexisting cholinergic and parahippocampal degeneration: a key to memory loss in dementia and a challenge for transgenic models? Neurodegener Dis 5:304-317.

Chao MV (2003) Neurotrophins and their receptors: a convergence point for many signalling pathways. Nat Rev Neurosci 4:299-309.

Chen KS, Nishimura MC, Armanini MP, Crowley C, Spencer SD, Phillips HS (1997) Disruption of a single allele of the nerve growth factor gene results in atrophy of basal forebrain cholinergic neurons and memory deficits. J Neurosci 17:7288-7296.

Dawbarn D, Allen SJ, Semenenko FM (1988) Coexistence of choline acetyltransferase and nerve growth factor receptors in the rat basal forebrain. Neurosci Lett 94:138-144.

Dechant G, Barde YA (2002) The neurotrophin receptor p75(NTR): novel functions and implications for diseases of the nervous system. Nat Neurosci 5:1131-1136.

Formaggio E, Fazzini F, Dalfini AC, Di Chio M, Cantù C, Decimo I, Fiorini Z, Fumagalli G, Chiamulera C (2010) Nicotine increases the expression of neurotrophin receptor tyrosine kinase receptor $\mathrm{A}$ in basal forebrain cholinergic neurons. Neuroscience 166:580-589.

Greferath U, Bennie A, Kourakis A, Barrett GL (2000) Impaired spatial learning in aged rats is associated with loss of p75-positive neurons in the basal forebrain. Neuroscience 100:363-373.

Hartikka J, Hefti F (1988a) Comparison of nerve growth factor's effects on development of septum, striatum, and nucleus basalis cholinergic neurons in vitro. J Neurosci Res 21:352-364.
Hartikka J, Hefti F (1988b) Development of septal cholinergic neurons in culture: plating density and glial cells modulate effects of NGF on survival, fiber growth, and expression of transmitter-specific enzymes. J Neurosci 8:2967-2985

Heckers S, Ohtake T, Wiley RG, Lappi DA, Geula C, Mesulam MM (1994) Complete and selective cholinergic denervation of rat neocortex and hippocampus but not amygdala by an immunotoxin against the p75 NGF receptor. J Neurosci 14:1271-1289.

Hollnagel A, Oehlmann V, Heymer J, Rüther U, Nordheim A (1999) Id genes are direct targets of bone morphogenetic protein induction in embryonic stem cells. J Biol Chem 274:19838-19845.

Kanning KC, Hudson M, Amieux PS, Wiley JC, Bothwell M, Schecterson LC (2003) Proteolytic processing of the p75 neurotrophin receptor and two homologs generates C-terminal fragments with signaling capability. J Neurosci 23:5425-5436.

Koh S, Chang P, Collier TJ, Loy R (1989) Loss of NGF receptor immunoreactivity in basal forebrain neurons of aged rats: correlation with spatial memory impairment. Brain Res 498:397-404.

Large TH, Bodary SC, Clegg DO, Weskamp G, Otten U, Reichardt LF (1986) Nerve growth factor gene expression in the developing rat brain. Science 234:352-355.

Lauterborn JC, Isackson PJ, Gall CM (1991) Nerve growth factor mRNAcontaining cells are distributed within regions of cholinergic neurons in the rat basal forebrain. J Comp Neurol 306:439-446.

Lauterborn JC, Bizon JL, Tran TM, Gall CM (1995) NGF mRNA is expressed by GABAergic but not cholinergic neurons in rat basal forebrain. J Comp Neurol 360:454-462.

Leanza G, Nilsson OG, Nikkhah G, Wiley RG, Björklund A (1996) Effects of neonatal lesions of the basal forebrain cholinergic system by $192 \mathrm{immu}-$ noglobulin G-saporin: biochemical, behavioural and morphological characterization. Neuroscience 74:119-141.

Li Y, Holtzman DM, Kromer LF, Kaplan DR, Chua-Couzens J, Clary DO, Knüsel B, Mobley WC (1995) Regulation of TrkA and ChAT expression in developing rat basal forebrain: evidence that both exogenous and endogenous NGF regulate differentiation of cholinergic neurons. J Neurosci 15:2888-2905.

Lin PY, Hinterneder JM, Rollor SR, Birren SJ (2007) Non-cell-autonomous regulation of GABAergic neuron development by neurotrophins and the p75 receptor. J Neurosci 27:12787-12796.

Linke R, Frotscher M (1993) Development of the rat septohippocampal projection: tracing with DiI and electron microscopy of identified growth cones. J Comp Neurol 332:69-88.

Liu A, Niswander LA (2005) Bone morphogenetic protein signalling and vertebrate nervous system development. Nat Rev Neurosci 6:945-954.

López-Coviella I, Berse B, Krauss R, Thies RS, Blusztajn JK (2000) Induction and maintenance of the neuronal cholinergic phenotype in the central nervous system by BMP-9. Science 289:313-316.

López-Coviella I, Follettie MT, Mellott TJ, Kovacheva VP, Slack BE, Diesl V, Berse B, Thies RS, Blusztajn JK (2005) Bone morphogenetic protein 9 induces the transcriptome of basal forebrain cholinergic neurons. Proc Natl Acad Sci U S A 102:6984-6989.

López-Coviella I, Mellott TM, Kovacheva VP, Berse B, Slack BE, Zemelko V, Schnitzler A, Blusztajn JK (2006) Developmental pattern of expression of BMP receptors and Smads and activation of Smad1 and Smad5 by BMP9 in mouse basal forebrain. Brain Res 1088:49-56.

Lüesse HG, Roskoden T, Linke R, Otten U, Heese K, Schwegler H (1998) Modulation of mRNA expression of the neurotrophins of the nerve growth factor family and their receptors in the septum and hippocampus of rats after transient postnatal thyroxine treatment. I. Expression of nerve growth factor, brain-derived neurotrophic factor, neurotrophin-3, and neurotrophin 4 mRNA. Exp Brain Res 119:1-8.

Magal E, Burnham P, Varon S (1991) Effect of CNTF on low-affinity NGF receptor expression by cultured neurons from different rat brain regions. J Neurosci Res 30:560-566.

Massagué J (2008) TGFbeta in Cancer. Cell 134:215-230.

Mobley WC, Rutkowski JL, Tennekoon GI, Gemski J, Buchanan K, Johnston MV (1986) Nerve growth factor increases choline acetyltransferase activity in developing basal forebrain neurons. Brain Res 387:53-62.

Mufson EJ, Counts SE, Perez SE, Ginsberg SD (2008) Cholinergic system during the progression of Alzheimer's disease: therapeutic implications. Expert Rev Neurother 8:1703-1718.

Nonner D, Barrett EF, Kaplan P, Barrett JN (2001) Bone morphogenetic 
proteins (BMP6 and BMP7) enhance the protective effect of neurotrophins on cultured septal cholinergic neurons during hypoglycemia. J Neurochem 77:691-699.

Ricceri L, Hohmann C, Berger-Sweeney J (2002) Early neonatal 192 IgG saporin induces learning impairments and disrupts cortical morphogenesis in rats. Brain Res 954:160-172.

Saadat S, Sendtner M, Rohrer H (1989) Ciliary neurotrophic factor induces cholinergic differentiation of rat sympathetic neurons in culture. J Cell Biol 108:1807-1816.

Saporito MS, Carswell S (1995) High levels of synthesis and local effects of nerve growth factor in the septal region of the adult rat brain. J Neurosci 15:2280-2286.

Saporito MS, Brown ER, Hartpence KC, Wilcox HM, Robbins E, Vaught JL, Carswell S (1994) Systemic dexamethasone administration increases septal Trk autophosphorylation in adult rats via an induction of nerve growth factor. Mol Pharmacol 45:395-401.

Schnitzler AC, Lopez-Coviella I, Blusztajn JK (2008a) Differential modulation of nerve growth factor receptor (p75) and cholinergic gene expression in purified p75-expressing and non-expressing basal forebrain neurons by BMP9. Brain Res 1246:19-28.

Schnitzler AC, Lopez-Coviella I, Blusztajn JK (2008b) Purification and culture of nerve growth factor receptor (p75)-expressing basal forebrain cholinergic neurons. Nat Protoc 3:34-40.

Semkova I, Krieglstein J (1999) Ciliary neurotrophic factor enhances the expression of NGF and p75 low-affinity NGF receptor in astrocytes. Brain Res 838:184-192.

Shelton DL, Reichardt LF (1986) Studies on the expression of the beta nerve growth factor (NGF) gene in the central nervous system: level and re- gional distribution of NGF mRNA suggest that NGF functions as a trophic factor for several distinct populations of neurons. Proc Natl Acad Sci U S A 83:2714-2718.

Sofroniew MV, Howe CL, Mobley WC (2001) Nerve growth factor signaling, neuroprotection, and neural repair. Annu Rev Neurosci 24:12171281.

Tallini YN, Shui B, Greene KS, Deng KY, Doran R, Fisher PJ, Zipfel W, Kotlikoff MI (2006) BAC transgenic mice express enhanced green fluorescent protein in central and peripheral cholinergic neurons. Physiol Genomics 27:391-397.

Tuszynski MH, Thal L, Pay M, Salmon DP, U HS, Bakay R, Patel P, Blesch A, Vahlsing HL, Ho G, Tong G, Potkin SG, Fallon J, Hansen L, Mufson EJ, Kordower JH, Gall C, Conner J (2005) A phase 1 clinical trial of nerve growth factor gene therapy for Alzheimer disease. Nat Med 11:551-555.

Upton PD, Davies RJ, Trembath RC, Morrell NW (2009) Bone morphogenetic protein (BMP) and activin type II receptors balance BMP9 signals mediated by activin receptor-like kinase- 1 in human pulmonary artery endothelial cells. J Biol Chem 284:15794-15804.

Weskamp G, Schlöndorff J, Lum L, Becherer JD, Kim TW, Saftig P, Hartmann D, Murphy G, Blobel CP (2004) Evidence for a critical role of the tumor necrosis factor $\alpha$ convertase (TACE) in ectodomain shedding of the p75 neurotrophin receptor (p75 NTR). J Biol Chem 279:4241-4249.

Wu H, Friedman WJ, Dreyfus CF (2004) Differential regulation of neurotrophin expression in basal forebrain astrocytes by neuronal signals. J Neurosci Res 76:76-85.

Yu PB, Hong CC, Sachidanandan C, Babitt JL, Deng DY, Hoyng SA, Lin HY, Bloch KD, Peterson RT (2008) Dorsomorphin inhibits BMP signals required for embryogenesis and iron metabolism. Nat Chem Biol 4:33-41. 